\title{
Social Media Content: A Management Framework
}

\author{
Maria Giovanna Confetto ${ }^{1} \&$ Alfonso Siano ${ }^{1}$ \\ ${ }^{1}$ Department of Political, Social and Communication Sciences, University of Salerno, Italy \\ Correspondence: Maria Giovanna Confetto, Department of Political, Social and Communication Sciences, \\ University of Salerno, Italy. E-mail: mconfetto@unisa.it
}

Received: February 7, 2018

Accepted: April 20, 2018

Online Published: May 15, 2018

doi:10.5539/ijbm.v13n6p84

URL: https://doi.org/10.5539/ijbm.v13n6p84

\begin{abstract}
This paper aims to introduce a model for social media content management that is focused on both the strategic and operational levels to guide companies in setting, formulating and spreading social media marketing content and monitoring the achieved results. The framework has been realized considering different cognitive goals related to the organizational unit responsible of the development of the content marketing processes, corporate content identity, decision making elements for digital content creation, the diffusion of content through social media platforms, and the tools and parameters used to measure and evaluate performance. The model presented here is an attempt to fill in the existing gap in the recent literature regarding digital content marketing and social media content management. The framework introduces some consequential steps of a well-defined process that is composed of decisions and activities that must be carefully planned, thus preventing (from an operational level) the recurrent use of specific management tools. By adopting an integrated vision, is it possible to keep the business strategy's objectives and all the operative tasks conducted by the content marketing team aligned.
\end{abstract}

Keywords: framework, management, social media content, content marketing

\section{Introduction}

Thanks to the constant progress in the ICT field and to the diffusion of social media platforms, there are new opportunities for interactions between companies and their target audiences. This contributes to the organization and the rise of new business models where a central role is given to consumers who are seen as guides and active partners in the marketing process (Tuten \& Solomon, 2015). It also reshapes and rethinks the role and meaning of corporate communications (Cornelissen, 2017). The so-called "new media" (Flew, 2008) are no longer representing just a technological innovation but are conceived as the main instrument of a cultural and social revolution that had and is still having an important impact on the evolution of consumption, markets and the economy.

From a technological point of view, digital convergence has offered everyone the concrete chance to enjoy dematerialized content through a wide range of devices and create their own contributions (user-generated content) (Kaplan \& Haenlein, 2010).

From a socio-cultural perspective, the possibilities offered to users to find all the information they need online and to confront and share their purchases and consumption decisions is leading to the emergence of new habits and needs of the post-consumer (Pilotti \& Tedeschi Toschi, 2014). It considers an individual who, having gained several consumer experiences, has now become more competent, selective, autonomous and less influenced in his/her choices and more inclined to express his/her personal point of view on the brands and products inside his/her own community.

The wide connections offered by the Web are facilitating people's empowerment (Füller, Mühlbacher, Matzler, \& Jawecki, 2009) and the consequential increase in the competition regarding the generation of editorial content and products. Internet users are expressing themselves through an uncontrolled amount of content of different types (opinions, suggestions, reviews, etc.) and are boosting the information and cognitive overload (Meyer, 1998). This makes it more difficult to identify the real value enclosed in each message and to make consumer choices (Broniarczyk \& Griffin, 2014). In this way, it is diminishing the individual's ability to focus on the existing information, especially with respect to commercial ads.

As a direct consequence, companies are losing efficiency related to traditional market logic. They need to focus and redirect corporate communications to a more active and participative role for each individual in the 
corporate strategy. Furthermore, they must urgently and constantly listen to and interact with them for the co-creation and diffusion of digital content.

This phenomenon linked to the interaction through the sharing of content is leading to new and interesting fields of research. Sharing is not conceived as "sharing with others" but as transforming content for a "common good" whose value is increased by others' involvement (Tuten \& Solomon, 2015). Considering all these trends, it is evident that the existing competitive advantages are more dependent upon the company's ability to build, organize and share high-quality content. The content may be informational and/or entertaining. It may not be explicitly commercial in nature but is user-centered, since it is the source of cognitive and emotional value for those who are using it. Therefore, the main themes of digital content marketing (Koiso-Kanttila, 2004; Rowley, 2008; Ryan, 2016) and social media marketing (Evans, 2010; Tuten \& Solomon, 2015; Hyder, 2016) are gaining centrality for scholars and practitioners and for all companies operating or willing to operate online. For the latter, focusing their resources and energies on digital content (Frick, 2010; Taylor, 2012; Leeflang, Verhoef, Dahlström \& Freundt, 2014) can represent an answer to effectively face the online consumer empowerment to trigger new value-creation mechanisms and to activate innovative processes for stakeholder engagement (Krick, Forstater, Monaghan, \& Sillanpää, 2005).

Social media's interactive and multimedial dimension can offer the ideal ground for complete expression (Smith, 2009; Laurita \& Venturini, 2014). Thanks to social media, companies can connect themselves with other people and choose the style and approach most suited for direct discussions with these communities of users (Hanna, Rohm \& Crittenden, 2011) with no restrictions in terms of space or time. In this perspective, communications through social media become the preferred tool to generate and foster personalized and continuative interactions (contacts) between organizations and stakeholders in order to focus users' attention on specific themes of shared interest, to stimulate positive emotions and perceptions and to enhance the brand's reliability and authority.

However, creating and using digital content is not an automatic or standardized process, but it can vary according to several factors. For this reason, it is essential be able to plan a real digital content strategy that can help to optimally manage all activities linked to social media content (de Wit \& Meyer, 2010; Halvorson \& Rach, 2012; Ashley \& Tuten, 2015). It is essential to be able to separate the upstream content from the beginning roles and resources and define the objectives and target audience in order to select the appropriate publishing vehicles, methods and times. Then, it is vital to select the best measurement metrics and indicators to evaluate the obtained results.

In the existing literature, there is no framework showing the steps for the correct setup and implementation of social media content. This issue becomes particularly relevant in a historic moment when content marketing is rapidly spreading (Handley \& Chapman, 2012; Pulizzi, 2014; Ryan, 2016).

Currently, there are no tools to simplify the task assigned to companies with respect to the problems related to the complexity and heaviness in managing the many variables that impact digital contents' efficiency. Among these variables, we may find and include the varied public and specific objectives to be reached, the different technologies of the various social media platforms, the distinctiveness of several kinds of content, the ability to coordinate final objectives, the public and vehicular mix, and the existing complexity related both to feedback decodification and performance indicators. So far, the characteristic building-blocks from the models proposed in the literature (even when highlighting all the elements that have to characterize a content marketing plan) do not seem to be a complete guide for content lifecycle management.

Therefore, this paper intends to fill this gap by proposing a framework showing the sequence of activities and decisions that are differentiated on a strategic and operational level for the creation, diffusion and control of digital content in order to construct long-lasting relationships with the social Web audience.

The paper is structured as follows. First, it will present the literature review about digital content marketing and consider the deep changes that it has produced in corporate communications. The emerging conceptual background will be the basis upon which we define the cognitive goals of the research and create the model. Then, it will construct the process of management social media content that will illustrate the three phases that will form the final framework. Lastly, we will introduce the implications derived from the use of the model and some conclusive observations.

\section{Literature Review and Cognitive Goals Development}

\subsection{Social Media and Digital Content Marketing}

The evolution of the Net with respect to Web 2.0 has significantly modified the ways of accessing and using information. This is a main consequence of the democratization of online content production and distribution 
(O'Reilly, 2005; Gorry \& Westbrook, 2009), since it is reflected by the diffusion of the phenomenon known as user-generated content (Blank, 2013; Singer, 2014).

The chance to express ideas, opinions and the associated consumer empowerment (Kucuk \& Krishnamurthy, 2007) implies that companies need to reorganize their internal structures in order to rapidly and directly learn the changes that are emerging in the markets through online interactions and conversations in the sphere of organized listening (Schultz \& Kitchen, 2004).

This situation leads to the need to rethink traditional marketing and company communication models and privilege the logic based on the creation and diffusion of high value quality content inside interactive and participative social Web contexts (Pulizzi \& Barrett, 2009; Lecinski, 2011). In this logic, the shift toward enterprise 2.0 (McAfee, 2009) (in other words, the utilization by organizations of new social software platforms to reach their objectives) is justified for the sake of the visibility, promotion and the commercialization of goods and services as well as for the exchange of information with users, diffused involvement and collaboration to build strong and trustworthy relationships (Rowley, 2008; Winer, 2009).

The purpose to shift the focus from advertisements to content quality to share with the public might be considered an opportunity to introduce some commercial ads, which is something that is revealing the concrete opportunity for the companies to act as publishers (Lieb, 2012) or as editors of enterprise-generated content (Dubini \& Prestinari, 2008) or branded content (Nelli, 2012; Choi, 2015). We are dealing with original content that together with a persuasive intention, is also encompassing new stimuli to emotionally entertain, engage, and retain the audience target. Such content that is offered in the "pull mode" can attract buyers and stakeholders that share some general intellectual affinity or engagement with the brand.

Through the interactions linked to the active and continuous exchange of social media content, the company can observe and collect data with a supportive role in the process devoted to building and growing a community of (potential) customers and to developing and consolidating a positive corporate reputation.

In this context, we can reference digital content marketing activities whose literature has offered different kinds of contributions (texts, papers, reports, and statistics) both in the academic field (Koiso-Kanttila, 2004; Rowley, 2008; Gordini \& Rancati, 2015; Siano, Fiocca, \& Pastore, 2015; etc.) and on an operational level, thanks to the input offered by practitioners (Handley \& Chapman, 2012; Funk, 2013; Scott, 2015; Pulizzi, 2014). The wide variety of contributions dealing with digital content marketing has a kind of double value or interpretation. It can express the richness of the existing approaches and scopes, but it does not facilitate any attempt to give order to this subject.

As for now, it seems that there is no widely accepted orientation regarding the conceptualization of content marketing in the digital environment (Vollero \& Palazzo, 2015). By analyzing the literature, it is possible to find several definitions, and each of them focuses on different aspects of this new marketing approach. Among the most quoted, we can find the following:

- "The management process responsible for identifying, anticipating, and satisfying customer requirements profitably in the context of digital content, or bit-based objects distributed through electronic channels" (Rowley, 2008);

- "A strategy focused on the creation of a valuable experience" (Rose \& Pulizzi, 2011);

- "The discipline of creating quality branded content across media channels and platforms to deliver engaging relationships, consumer value and measurable success for brands" (Content Marketing Association, 2013);

- "Involves creating, distributing and sharing relevant, compelling and timely content to engage customers at the appropriate point in their buying consideration processes, such that it encourages them to convert to a business building outcome" (Holliman \& Rowley, 2014);

- "The overarching practice of using information and entertainment to promote a brand or product" (DeMers, 2014); and

- "A strategic marketing approach focused on creating and distributing valuable, relevant, and consistent content to attract and retain a clearly defined audience - and, ultimately, to drive profitable customer action" (Content Marketing Institute, 2015).

Considering these definitions, we first identify the emerging characteristics that digital content should present (educational, compelling, relevant, and consistent) and the achievable objectives (identify, anticipate and satisfy customer requirements, attract and retain customers, deliver engaging relationships, promote a brand or product, and drive profitable customer actions). However, it is not clear which activities should be adopted for digital content marketing. 
For some, it only concerns the content creation in different digital formats. For others, it also addresses the distribution and sharing through multiple platforms. Furthermore, for others, it also includes the activities aimed to track and measure the achieved results. It lacks a shared position regarding the nature of digital content marketing or the role that it can assume inside a wider communication and business strategy.

In the literature on this subject (particularly the Anglo-Saxon literature), it is quite common that the general definition of "digital content strategy" includes both strategic elements (as those structural features that can be planned over a long-term period) and operational ones (with reference to the utilization of structural strategic elements in a short-middle period) (Handley \& Chapman, 2012; Halvorson \& Rach, 2012; Pulizzi, 2014; Nelli, 2012). The majority of the contributions on this theme emphasize the need to define a process of strategic planning for content marketing. Some of the models proposed in the literature (Pulizzi \& Barrett, 2009; Rose \& Pulizzi, 2011; Nelli, 2012; Halvorson \& Rach, 2012) are devoted to showing some fundamental steps, including defining objectives and individuating target audiences (usually with reference to the strategic planning), creating and sharing content, monitoring feedback and analyzing results as operational activities. In this direction are the so-called quad (Halvorson \& Rach, 2012) and the hub \& spoke (Odden, 2012). The former represents a tool that can guide the identification of the critical components of the content strategy. The latter can be considered a planning tool functional to the choice of the vehicle that functions as a hub that is the pivotal element from which originates the content strategy's activities and all the vehicles that are functional for the diffusion (spoke) of the contents.

Conversely, many content marketing practitioners acknowledge an innovative approach to adopt the practice of marketing communications (Scott, 2015; Gavatorta \& Maestri, 2013; DeMers, 2014; Content Marketing Association, 2013). Considering the operational level, content marketing can be described as functional to the achievement of specific communicative objectives (e.g., brand awareness and stakeholder engagement) (Cope, 2014). It is intended to be the main aspect of integrated marketing communication strategies (Pulizzi, 2014) or as a tactic to be actuated within wider inbound marketing strategies (Lieberman, 2016).

The variety of orientations in content marketing suggests the need to adopt an integrated approach in order to redirect decisions and activities concerning the production and distribution of content, both on a strategic and operational level.

\subsection{Strategic Management and Operational Management in Corporate Communication Decisions}

Recently, the awareness among academics and practitioners of the even more determining role of business communication for companies' competitiveness has grown. The reputation and the success of an organization are strictly dependent on the "new" supportive habits that are emerging online, such as sharing ideas, "defending" organizational opinions, and the positive influences (via suggestions, tips, etc.) based on the choices of other stakeholders (Dijkmans, Kerkhof \& Beukeboom, 2015). This scenario implies a new conception of communication that is no longer operational but is strategic and "resource-holder-oriented". The communicative activities are built by adopting an interactive approach (Welch \& Jackson, 2007) based on symmetrical relationships with different resource-holders that by sharing their own varied experiences in a dialogue with the company, can contribute to the definition of priorities in the communicative process. Therefore, deep changes are innovating the logic of corporate communications at both the levels of operations and strategic management (Siano, Vollero, Confetto, \& Siglioccolo, 2013).

A first significant change concerns the corporal communication organizational unit. Taking the correct decision in terms of communications differentiates the contributions and the consequential involvement of many other subjects (CEO, communication counselors, general manager, and other top executives) (Argenti, 2007). In this context, we address the special relevance of the role of the communications professional (Chief Communication Officer and/or external communication counselor) that handles the company's dominant coalition (Bowen, 2009; Johansson \& Ottestig, 2011). This professional is in charge of following strategic procedures as organized listening activities (Golinelli, 2010) and the strategic reflection of these activities (van Ruler \& Vercic, 2005). From these, it is possible to gain useful information in terms of vision and corporate culture and to align the business strategy to the dynamics of the surrounding environment. In this way, it is acknowledged and affirmed that the "strategic" ability of these communicative activities orients the choices of management, supports the main business decision processes and formulates the corporate strategy (Lurati \& Eppler, 2006; Invernizzi \& Romenti, 2011). In contrast, the allocation of the communicative resources defined on a strategic level is related to the operational management.

In the context of digital communication, even the process of social media content's management requires the integration of the decisions and activities of strategic management and operational management. For this reason, 
the first cognitive goal of the present work (ob1) concerns the comprehension of how the business unit in charge of developing content marketing's processes is organized. In other words, it defines which subjects are responsible for the decisions regarding the development of activities to be carried out on a strategic or operational level.

First, taking strategic decisions implies the key identity elements useful to expressing companies' distinctiveness and differentiating themselves from competitors (Golinelli, 2010). These decisions that are related to the creation and renovation of corporate identity resources and also their coordination are included among the policy decisions for their implementations in a medium-to-long term period (Parsons, 1956). Referring to social media content management, on this decisional level, it is essential to separate and coordinate content identity resources that are derived from the translation of the vision of the corporate culture and business strategy into corporate communication's identity elements. Therefore, the point is to define the central nucleus of the structural endowment (Golinelli, 2010) starting from which (on the basis of an integrated approach) we can organize all the following operational choices in terms of the content to be diffused. Thus, the second research objective of the study (ob2) is to identify which elements form the content identity set of resources for social media content management.

Content identity's resources can be used for the decisions and operational management (allocation decision) (Parson, 1956). The utilization of these resources is oriented to reach different kinds of goals, including lead generation, lead nurturing, brand awareness, engagement, sales, customer retention and loyalty, customer evangelism, up-sell and cross-sell, and more (Content Marketing Institute \& MarketingProfs, 2014). Using the resources implies the operating choices on the other factors related to the formulation and distribution of digital content. It is particularly good to distinguish between the moment of the creation of digital content and the moment in which such content is diffused among social platforms. In this way, the further research objectives of this paper specify the factors that should be considered in making decisions on social media content (ob3) and its distribution process (ob4).

Among the main objectives of the diffusion of social content is the sharing of business messages by the users of the Net. The act of sharing can give the brand messages the chance to be diffused within the social Web and become "contagious" (Berger, 2013), pervasive and able to reach the maximum number of people. The social Web allows for specific stakeholder groups to meet themselves and construct a relationship among each other, which requires personalized messages and functions to perform one or more operational objectives. Therefore, each piece of digital content can be declined and modified according to the selected posting platform that corresponds to one or more target group. The adherence between the subjects presented and the specific interest of the audience can positively increase the emotional value of the content consumption (Berger, 2014) and encourage individuals to directly activate the diffusion of social media content through the sharing. In this way, it increases the strong chain effect of word of mouth (Trusov, Bucklin \& Pauwels, 2009) with the relative consequences on brand notoriety.

As content sharing increases, its diffusion also increases. Consequently, its effects depart from the media with centralized management and impact the ability of the organization to have firm control on communications (Gorry \& Westbrook, 2009).

As shared content increases, its spread also increases. Consequently, its effects depart from centralized media and impact the organization's ability to maintain a firm control over communications (Gorry \& Westbrook, 2009). In social media content management, this can impose the need to implement all those activities useful to track the audience's perception of the brand. The tools used are comments, likes, replies, mentions, ratings, reviews, shares and all the evidence on electronic word of mouth, which are the main phenomena to share audience opinions (Brown, Broderick, \& Lee, 2007). Therefore, the last research objective (ob5) will cover all the techniques and tools for monitoring the emerging flows and measuring the results.

Following similar research objectives, this section of the paper will allow us to define a clear sequence of steps needed to create, deliver and control valuable business content. To this end, in the next section, some concepts that emerged from the literature analysis that guide the construction of the social media content management (SMCM) framework (Figure 1) will be discussed again. The main ones include the distinction of the management process in two areas (strategic and operational) (Lurati \& Eppler, 2006; Invernizzi \& Romenti, 2011), the quad (Halvorson \& Rach, 2012) and the hub \& spoke (Odden, 2012). The in-depth review of the academic contributions in this area helps to identify the identity of the elements that interpret the strategic orientation and define the content's identity. It can also allow us to investigate the technical specificities and ways of using multiple online platforms (websites, blogs, social networks and other social media) for content 
elaboration and diffusion, and the peculiarities of the wide variety of digital content that is diffused online (posts, articles, videos, infographics, webcasts and podcasts, storytelling, etc.).

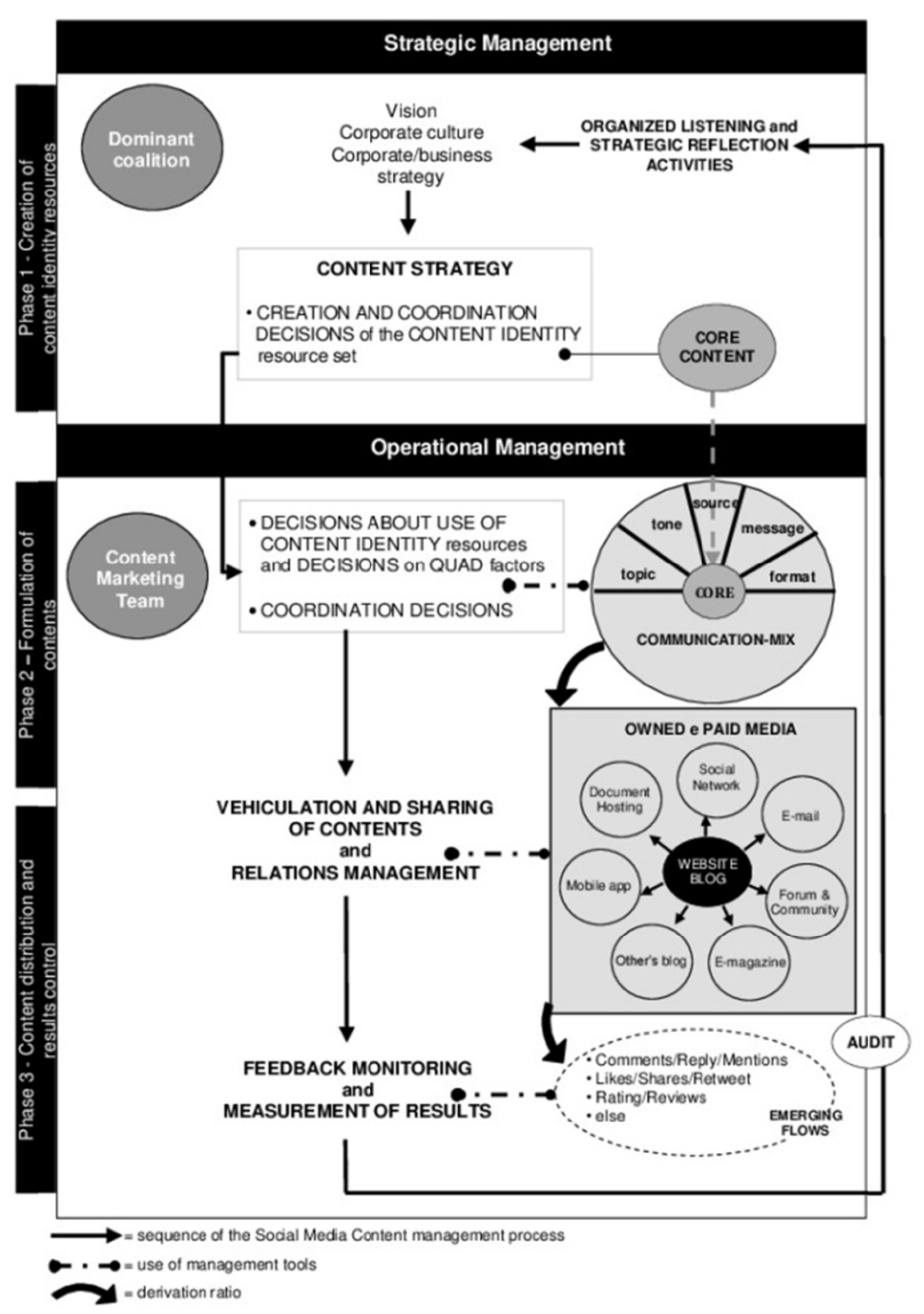

Figure 1. The social media content management (SMCM) framework

\section{Conceptual framework}

\subsection{Dominant Coalition and Content Marketing Team, Business Unit for Content Marketing}

To achieve the first cognitive goal (ob1) regarding the asset of the organizational unit responsible for content marketing processes, it must be emphasized that the centrality of content creation for corporate communication purposes has led to the rapid dissemination of more complex corporate organizational charts (especially medium-sized companies with specialized resources). These include new professional figures such as the Chief content Officer, the Content Marketing Specialist and the Chief Culture Officer, dealing with the management of owned and paid media and of the multi-channel publishing of content related to the organization. In this way, the management of content marketing processes requires the organization of a team of qualified professionals that is heterogeneous in terms of specific competences (such as the use of the web and its sociall platforms, the creation of digital content, search engine optimization, etc.). Although highly proficient, these professional resources need to be coordinated in their functions. For this reason, they are generally placed under the leadership of the Chief Communication Officer (CCO). As noted above, over the last few years, the communication manager has 
become part of the company's dominant coalition or the group of people responsible for the companies' governance, thanks to the direction they can transfer that is fundamental to strategic decisions. Moreover, due to this role, it is possible to ensure the alignment of business strategies with the dynamics actually emerging in the context of the social Web. To set up the SMCM framework, we assume the classic setting of the managerial field that (as for corporate communications management) distinguishes in two domains the social media content management process. The first area is related to the strategic management of content that focuses on the strategic role of corporate communications. This step starts from organized listening and strategic reflection, preliminary strategic activities from which the whole social media content management process encoded through the framework is derived. Strategic activities are the responsibility of the organization's dominant coalition, that is generally composed of the Chief Executive Officer (CEO), the Chief Communication Officer (CCO), and other top executives and communication consultants. From this, we can derive guidelines both for vision and corporate culture and for aligning business strategies with environmental dynamics. A second area is associated with operational management that is related to the allocation of strategic communication resources pertinent to the content marketing team. It is usually composed of the Chief content Officer (Cco) that has the task of overseeing all phases of the content marketing process and coordinating the elements and actors involved in this process to achieve established goals. Also included is the Managing Editor that manages the editorial functions, including preparing the web plan and editorial calendar, controlling the writing process and the content's online publishing, and other functions. Next is one or more Content Creators that develop content or identify and select existing ones and one or more Content Producers that address the aesthetics of content by giving them the most appropriate form to make them accessible to the public. Finally, the Chief Listening Officer oversees the content delivery across different platforms by listening, tracking, and participating in online conversations among users.

The composition of the content marketing team does not imply a strictly predetermined number of subjects or functions, nor is it delimited to the communication department. It may often include outsourced professionals.

\subsection{Creation of the Content Identity Set of Resources}

Strategic management and decision-making activities also include identifying the content identity set of resources (ob2) as an essential phase for the formulation and delivery of digital content. Through organized listening and strategic reflection activities, the input related to the needs and expectations of increasingly interconnected and interactive subjects are acquired and transferred to the dominant coalition for adequate information support for government decisions (about vision, corporate culture and business strategy). These two strategic communication activities allow to define the overall content strategy, that includes in the first instance to establish the objective of reputation that the company intends to pursue and, based on this, all the decisions for the creation and coordination of the content identity set of resources. This set of resources represents the central core of structural endowment (which can be defined by core content) from which it is possible to elaborate coherent content that is aligned with communications' strategic orientation.

Core content components can be divided in three categories: keywords and symbolic elements, owned digital media, and guidelines. Keywords represent the effective words upon which it is possible to build messages for social media content. They are distinguished by core themes that include basic elements or recurring themes for content elaboration (Cornelissen, 2017). Additionally, the brand mantra includes simple and short sentences that summarize the essence of the brand (Keller, Apéria, \& Georgson, 2008). The other two elements, owned media and guidelines, while being corporate identity resources, are functional to the use of keywords for content marketing purposes and for this reason they contribute to the core content. Owned digital media are the main online channels where content is "posted", and the company holds direct control of them. Generally, they are corporate websites, e-mails, corporate blogs, corporate social networking profiles, mobile apps, e-magazines, and more. Owned media represent the owned vehicles that are the preferred places for the diffusion of content with stakeholders and for interactions with them. Guidelines encompass rules to guide the behavior of the members of the organization regarding decision-making and communication activities. Therefore, they are essential for aligning content with the company's communication strategy.

These identity elements have to be mutually coordinated in accordance with the principles of integrated communication (Schultz, 1993). Furthermore, they must be consistent with the principles, values and priorities of the referring audience.

\subsection{Decisions for Content Elaboration and Diffusion}

The use of core content resources involves decision making and operational management activities pertaining to the content marketing team, especially those related to content elaboration. In this phase of the framework, the strategic objective of reputation can be achieved by reaching more and different operational goals (such as brand 
awareness, stakeholder engagement, lead generation and nurturing, customer retention, etc.). Once established which operational goals to pursue, it is necessary to decide how to use and allocate the resources of the core content in the elaboration of social media communications. Creating business content to be delivered to different audiences involves facing several choices about different factors. To get a better representation of the sequence of decisions, the model suggests to using the "quad" (a supportive decision tool) partially revised from the original version by Halvorson and Rach (2012). The composition of this management tool helps respond to the third cognitive goal (ob3). It consists of six sections, each of which corresponds to a decision about the use of selected items pertaining to core content: topic, tone, source, message, format and communication-mix. The topic is the issue to be treated in the content that must be interesting and coherent with the core business and relevant and useful for the user. Next, the tone of the voice to be used or the declination of the brand's voice is the "style" that reflects the corporate identity (Halvorson \& Rach, 2012; Handley \& Chapman, 2012), which depends on a series of variables (target audience, context of communication, topic, etc.). The tone of voice is useful to making the content relevant to both to the specific goals and to the reference audience, which gives them originality and personality. The tone of voice can be for example institutional and formal to express authoritative and expert brand personality or colloquial and friendly to express a young and dynamic brand personality. The source of the message is the subject that processes and communicates the content. Content can be original (created ad hoc by or for the company by content creators), co-created with relevant people within a given web community (influencers, opinion leaders, bloggers, video makers, etc.), created with a media company or with network users, or it may be third-party content (often user-generated content) adapted to be functional to the company's communication goals. The message is meant to be communicated through the content or the significant part (verbal, nonverbal, and iconic) that is constructed from the keywords defined in the strategic resource set. Also important is the format (or formats) in which the message may appear (text, image, video, or audio). Combining multiple formats into one creates hybrid formats that are defined by the digital content types (including infographics, e-books, video tutorials, webcasts, etc.). The communication mix addresses the identification of a number of elements that are integrated and coordinated. The stakeholder group to whom the communications are addressed, the techniques (such as online public relations, e-advertising, direct marketing, etc.), Internet medium and communication vehicles (website, blog, search engine, social network, etc.).

In the company's perspective, the published contents must aim at sharing by end users, an innovative and characterizing phenomenon of the online communication. Not surprisingly, this phase of the model focuses attention on sharing. The concept of online sharing is linked to the need of individuals to demonstrate to approve ideas, opinions, experiences of others and always manifests itself more often with the re-publication, in its own name, of a content published by other subjects (people or organizations). The sharing of business contents is the tangible demonstration of the effectiveness of management of Social Media Content. It is in this way that the visibility of the organization and its contents become dominant and allows coverage of a larger number of users.

To ensure contents' pervasiveness and virality, some vehicles (generally corporate websites or corporate blogs) must be considered as primary platforms that act as "centers" for publication and coordination of contents and their transmission. All other vehicles (social networks, e-mails, apps, e-magazines, other blogs, etc.) should instead be used as "rays" that can broadly propagate various content to all interested target audiences. To achieve the fourth cognitive goal (ob4) related to the content distribution process, we suggested the hub \& spoke distribution logic (Odden, 2012). Using this management tool makes it possible to deliver content and promote Internet sharing by utilizing the corporate website and corporate blog to increase and empower the various owned and paid media (social networks, mobile apps, emails, etc.). This can be analogously realized by some typical connections of the bicycle wheel (from the hub to the spoke and vice versa) that create the conditions for the development of the earned media (e-WOM, post comments, product reviews, etc.) that determine user-generated content and brand reputation.

\subsection{Feedback Monitoring and Results Evaluation}

To monitor and evaluate the effects of the distribution and diffusion of social media content, it is essential to detect, collect and analyze emerging communication flows through audit and social media analytic activities. In the relationship with users there is to consider that as you move away from centrally controlled media, such as the corporate website and the blog, and there goes into the world of social networks, forums and chats, the company reduces progressively its control degree of communication. Where websites and blogs are directly managed, social pages, forums and others social media involve a minor, if not zero, power of management/ control from the company. In this social environment, the expression of opinions, from spontaneous word of mouth among users and from the conversations that are established between these and the organization, a 
network of communication flows arises and they are defined as "emerging flows". Emerging flows are relevant because they not only have the power to influence (positively or not) the perceptions about the company of remaining parts of the public, but they often represent stimuli and suggestions useful for organized listening and for the strategic reflection activity of the company. As such, they have the power of modify fundamental corporate communication decisions, such as those relating to the creation and innovation of corporate and content identity resources. Collect, monitor and analyze online word of mouth and all the emerging flows in which it is manifested is a set of defined activities of Social Media Analytics included in the last phase of the proposed framework. With respect to the fifth and final goal (ob5), that defines the analytical techniques, tools, measurement parameters and key performance indicators (KPIs) (Table 1), the model suggests monitoring three areas in particular (Funk, 2013): the activities and behaviors of users within the social brand page, the activities and behaviors of users related to the brand and expressed in the social web in general, and the impact on the online business.

Users' activities and behaviors on social brand pages can be traced through the native social networking tools that provide statistics regarding audience size and how users interact with the content. A narrow analysis of the performance of the single platform needs to be expanded through techniques such as sentiment analysis, which is useful to monitor the (positive or negative) orientation of users' activities and behavior in the social Web in general. Ultimately, through web analytic tools, the consumption of social media content can be correlated to the overall online business trend (the use of the institutional website, purchasing processes and customer loyalty, etc.).

Table 1. Social media analytics: Summary chart

\begin{tabular}{|c|c|c|c|}
\hline & $\begin{array}{l}\text { Activities and Actions on the Brand } \\
\text { Page }\end{array}$ & $\begin{array}{l}\text { Activities and Actions } \\
\text { Referred to The Brand } \\
\text { in the Social Web }\end{array}$ & $\begin{array}{l}\text { Impact on the online } \\
\text { Business }\end{array}$ \\
\hline $\begin{array}{l}\text { Tracking and } \\
\text { Monitoring } \\
\text { Tools and } \\
\text { Instruments }\end{array}$ & $\begin{array}{l}\text { Analytic tools for single social media } \\
\text { platforms (e.g., Facebook Insights, } \\
\text { Twitter Analytics, etc.) }\end{array}$ & Sentiment analysis tools & $\begin{array}{l}\text { Web analytic tools (e.g., Google } \\
\text { Analytics) }\end{array}$ \\
\hline KPI Parameters & $\begin{array}{l}\text { - Audience dimension (fan, follower, } \\
\text { subscriber, leader, etc.); } \\
\text {-Content to uchpoints (likes, } \\
\text { comments, sharing, re-tweets, etc.) }\end{array}$ & $\begin{array}{l}\text { - strength } \\
\text { - sentiment } \\
\text { - passion } \\
\text { - reach }\end{array}$ & $\begin{array}{l}\text { - Content consumption (page view, } \\
\text { time spent visiting, bounce rate, etc.) } \\
\text { - Content sharing (like, tweet, re-tweet, } \\
\text { sharing, inbound links, etc.) } \\
\text { - Lead generation (contact forms filled } \\
\text { in, subscriptions, comments, etc.) } \\
\text { - Sales revenue (the abovementioned } \\
\text { KPIs, sales conversion rate, customer } \\
\text { acquisition cost, etc.) }\end{array}$ \\
\hline
\end{tabular}

The check phase allows for the detection and evaluation of the level of popularity and favorability that the brand carries on the Web. The results of the monitoring phase help to perceive emerging changes in the social, cultural, political and economic spheres. They also provide new input for the management by enabling the organization to take (where necessary) corrective actions such as innovating strategic content identity resources.

\section{Implications and Conclusion}

The SMCM framework seems to have interesting potential in terms of managerial implications. First, it highlights the close relationship between the strategic communication unit and the content marketing operational activities that conform to the core identity elements that construct the organization. Second, it correlates the decisions to be taken both in strategic and operational terms with the activities to be implemented. Furthermore, it distinguishes the roles and tasks in the implementation and realization of the content strategy.

Lastly, this research constitutes a guide for 1) the assumption of content creation decisions and for the correct sequence in which they have to follow (topic, tone, source, message, format, and communication mix); 2) defining the most suitable diffusion method for social content in order to increase the virility and opportunities of the content, thus facilitating the construction and management of strong and lasting relationships with the public; and 3) optimizing the relationship management by tracking feedback and measuring results. 
In addition, the framework allows us to integrate various marketing areas (web marketing, inbound marketing, e-mail marketing, video marketing, search engine marketing, e-commerce marketing, etc.). It is no coincidence that it acts as a coordination link between different business functions responsible for the development of the social media content process by preserving the coherence and corporate identity. The SMCM framework can be built on the circularity of the social media content management process, which highlights the need to transfer the results of audit activities to strategic management. The results of the audit activity help to detect any gap between goals and results by setting the basis for corrective actions in content management within the social Web. Therefore, circularity guarantees the alignment between the strategic business intent (expressed by the dominant coalition through core content) and the contents developed at the operational stage (in which the content marketing team is responsible).

The logical sequence of strategic and operational decisions and activities that characterize the SMCM model, and the identification of the three main phases in which it is articulated, is the first attempt at identifying a standard that drives social media content management within organizations. Therefore, it can represent a benchmark for digital communication managers and consultants.

Considering the conceptual nature of the paper, the model must be evaluated through future pilot studies that will test its applicability, functionality and empirical validity.

The implementation of pilot studies is necessary in view of the fact that it is urgent to quickly validate the model and make it available to companies and communication managers that will use it in a reality of increasing development of content marketing.

\section{References}

Argenti, P. A. (2007). Corporate communication (4th ed.). New York: McGraw-Hill.

Ashley, C., \& Tuten, T. (2015). Creative Strategies in Social Media Marketing: An Exploratory Study of Branded Social Content and Consumer Engagement. Psychology \& Marketing, 32(1), 15-27. https://doi.org/10.1002/mar.20761

Berger, J. (2013). Contagious. Why things catch on. New York: Simon \& Schuster.

Berger, J. (2014). Word of mouth and interpersonal communication: A review and directions for future research. Journal of Consumer Psychology, 4(24), 586-607. https://doi.org/10.1016/j.jcps.2014.05.002

Blank, G. (2013). Who creates content? Stratification and content creation on the Internet, Information, Communication \& Society, 16(4). https://doi.org/10.1080/1369118x.2013.777758

Bowen, S. A. (2009). What Communication Professionals Tell Us Regarding Dominant Coalition Access and Gaining Membership, Journal of Applied Communication Research, 37(4), 418-443. https://doi.org/10.1080/00909880903233184

Broniarczyk, S. M., \& Griffin, J. (2014). Decision Difficulty in the Age of Consumer Empowerment. Journal of Consumer Psychology, 24(4), 608-625. https://doi.org/10.1016/j.jcps.2014.05.003

Brown, J., Broderick, A. J., \& Lee, N. (2007). Word of mouth communication within online communities: Conceptualizing the online social network. Journal of Interactive Marketing, 21(3), 2-20. https://doi.org/10.1002/dir.20082

Choi, M. W. (2015). A Study on the Branded Content as Marketing Communication Media in the Viewpoint of Relational Perspective. Indian Journal of Science and Technology, 8(5), 116-123. https://doi.org/10.17485/ijst/2015/v8is5/61606

Content Marketing Association (2013). What is Content Marketing? Retrieved June 2017 from $\mathrm{http}: / / \mathrm{www}$.the-cma.com/news/what-is-content-marketing

Content Marketing Institute (n.d.). What is Content Marketing? Useful content should be at the core of your marketing. Retrieved June 2017 from Content Marketing Institute website, $\mathrm{http}: / /$ contentmarketinginstitute.com/what-is-content-marketing/

Content Marketing Institute \& MarketingProfs (2014). B2C Content Marketing 2015. Benchmarks, Budgets and Trends-North America. ARetrieved August 2017 from http://contentmarketinginstitute.com/wp-content/uploads/2014/10/2015_B2C_Research.pdf

Cope, L. (2014). Why Your Branded Content Shouldn't Always Be About Your Brand. Retrieved August 2016 from http://contentmarketinginstitute.com/2014/03/branded-content-shouldnt-always-be-about-brand/ 
Cornelissen, J. (2017). Corporate communication. A guide to theory and practice. London: Sage Publications Ltd.

De Wit, B., \& Meyer, R. (2010). Strategy: Process, Content, Context. An International Perspective (4th ed.). Cheriton House, North Way, Andover, Hampshire, U.K.: Cengage Learning EMEA.

Demers, J. (2014). The top 7 content marketing trends dominating 2014. Forbes. Retrieved June 2017 from http://www.forbes.com/sites/jaysondemers/2014/08/19/the-top-7-content-marketing-trends-dominating-201 4

Dijkmans, C., Kerkhof, P., \& Beukeboom, C. J. (2015). A stage to engage: Social media use and corporate reputation. Tourism Management, 47, 58-67. https://doi.org/10.1016/j.tourman.2014.09.005

Dubini, P., \& Prestinari, P. (2008). Enterprise Generated Content: le imprese diventano editori. Milano: Workshop SMA.

Evans, D. (2010). Social Media Marketing: The Next Generation of Business Engagement (1st ed.). Indiana: Wiley Publishing Inc.

Flew, T. (2008). New Media: An Introduction. Oxford: Oxford University Press.

Frick, T. (2010). Return on engagement: Content, strategy, and design techniques for digital marketing. United States of America: Elsevier Inc.

Füller, J., Mühlbacher, H., Matzler, K., \& Jawecki, G. (2009). Consumer Empowerment through Internet-Based Co-creation. Journal of Management Information Systems, 26(3), 71-102. https://doi.org/10.2753/mis0742-1222260303

Funk, T. (2013). Advanced Social Media Marketing. New York: Apress.

Gavatorta, F., \& Maestri, A. (2013). Digital Content Marketing. Torino: Anteprima ed.

Golinelli, G. M. (2010). Viable Systems Approach (VSA). Governing Business Dynamic. Padova: Cedam-Kluwer.

Gordini, N., \& Rancati, E. (2014). Content Marketing e Creazione di Valore: Aspetti Definitori e Metriche di Misurazione. Torino: Giappichelli.

Gorry, G. A., \& Westbrook, R. A. (2009). Winning the Internet Confidence Game. Corporate Reputation Review, 12(3), 195-203. https://doi.org/10.1057/crr.2009.16

Hallan, K, Holtzhausen, D., Van Ruler, B., Vercic, D., \& Sriramesh, K. (2007). Defining Strategic Communication. International Journal of Strategic Communication, 1(1), 3-35. https://doi.org/10.1080/15531180701285244

Halvorson, K., \& Rach, M. (2012). Content Strategy for the web. Berkeley: New Riders ed.

Handley, A., \& Chapman, C.C. (2012). Content Marketing. Fare business con i contenuti per il web. Milano: Hoepli.

Hanna, R., Rohm, A., \& Crittenden, V. L. (2011). We're all connected: The power of the social media ecosystem. Business Horizons, 54(3), 265-273. https://doi.org/10.1016/j.bushor.2011.01.007

Holliman, G., \& Rowley, J. (2014). Business to business digital content marketing: marketers' perceptions of best practice. Journal of Research in Interactive Marketing, 8(4), 269-293. https://doi.org/10.1108/jrim-02-2014-0013

Hyder, S. (2016). The zen of social media marketing: An easier way to build credibility, generate buzz, and increase revenue. Dallas: BenBella Books, Inc.

Invernizzi, E., \& Romenti, S. (2011). Strategic Communication and Decision-Making Processes. Toward the Communication Oriented Organisation. Academicus International Scientific Journal, 3, 12-27. https://doi.org/10.7336/academicus.2011.03.01

Johansson, C., \& Ottestig, A. T. (2011). Communication executives in a changing world: Legitimacy beyond organizational borders. Journal of Communication Management, 15(2), 144-164. https://doi.org/10.1108/13632541111126364

Kaplan, A. M., \& Haenlein M. (2009). Users of the world, unite! The challenges and opportunities of Social Media. Business Horizons Journal, 53(1), 59-68. https://doi.org/10.1016/j.bushor.2009.09.003

Keller, K. L., Apéria, T., \& Georgson, M. (2008). Strategic Brand Management: a European Perspective. Harlow, United Kingdom: Pearson Education Limited. 
Koiso-Kanttila, N. (2004). Digital Content Marketing: A Literature Synthesis. Journal of Marketing Management, 20(1/2), 45-65. https://doi.org/10.1362/026725704773041122

Krick, T., Forstater, M., Monaghan, P., \& Sillanpää, M. (2005). The stakeholder engagement manual volume 2: The practitioners handbook on stakeholder engagement. Account-Ability. The United Nations Environment Programme \& Stakeholder Research Associates.

Kucuk, S. U., \& Krishnamurthy, S. (2007). An Analysis of Consumer Power on the Internet. Technovation, 27(1/2), 47-56. https://doi.org/10.1016/j.technovation.2006.05.002

Laurita, G., \& Venturini, R. (2014). Strategia digitale: Il manuale per comunicare in modo efficace su internet e social media. Milano: Ulrico Hoepli Editore.

Lecinski, J. (2011). ZMOT - Winning the Zero Moment of Truth, Google Inc.

Leeflang, P. S. H., Verhoef, P., Dahlstrom, P., \& Freundt, T. (2014). Challenges and solutions for marketing in a digital era. European Management Journal,31(1), 1-12. https://doi.org/10.1016/j.emj.2013.12.001

Lieb, R. (2012). Think like a publisher. United States: Que Publishing.

Lieberman, M. (2016). The Difference Between Content Marketing and Inbound Marketing. Retrieved September 2016 from http://www.square2marketing.com/blog/bid/145625/The-Difference-Between-Content-Marketing-and-Inbo und-Marketing

Lurati, F., \& Eppler, M. J. (2006). Communication and management: researching corporate communication and knowledge communication in organizational setting. Studies in Communication Sciences, 6(2), 75-98.

McAfee, A. (2009). Enterprise 2.0: New collaborative tools for your organization's toughest challenges. Boston: Harvard Business Press.

Meyer, J., (1998). Information overload in marketing management. Marketing Intelligence \& Planning, 16(3), 200-209. https://doi.org/10.1108/02634509810217318

Nelli, R. P. (2012). Branded Content Marketing. Un nuovo approccio alla creazione di valore. Milano: Vita \& Pensiero.

Nowak, G. J., \& Phelps J., (1994). The Integrated Marketing Communications' Phenomenon: An Examination of Its Impact on Advertising Practices and Its Implications for Advertising Research. Journal of Current Issues and Research in Advertising, 16(1), 49-66.

O'Reilly, T. (2005, September 30). What is Web 2.0. Retrieved July 2016 from http://www.oreilly.com/pub/a/web2/archive/what-is-web-20.html?page=1

Odden, L. (2012). Optimize: How to Attract and Engage More Customers by Integrating SEO, Social Media, and Content Marketing. New Jerse: John Wiley \& Sons Inc.

Parsons, T. (1956). Suggestions for a sociological approach to the theory of organizations. Administrative Science Quarterly, 1(1), 63-85. https://doi.org/10.2307/2390988

Pilotti, L., Tedeschi Tosch, A. (curated by) (2014). Prefazione all'edizione italiana. In T. L. Tuten, M. R. Solomon. Social Media Marketing. Post-consumo, innovazione collaborativa e valore condiviso. Milano: Pearson Italia.

Pulizzi, J. (2014). Epic Content Marketing. United States: McGraw-Hill Education.

Pulizzi, J., \& Barrett, N. (2009). Get content Get customers. United States: McGraw-Hill Education.

Rose, R., \& Pulizzi, J. (2011). Managing Content Marketing: The Real-World Guide for Creating Passionate Subscribers to Your Brand. Cleveland Ohio: CMI books.

Rowley, J. (2008). Understanding digital content marketing. Journal of Marketing Management, 24(5/6), 517-540. https://doi.org/10.1362/026725708x325977

Ryan, D. (2016). Understanding digital marketing: marketing strategies for engaging the digital generation. United States: Kogan Page Limited.

Schultz, D. E. (1993). Integrated Marketing Communications: Maybe Definition Is in the Point of View. Marketing News, 27(2), 17-18.

Schultz, D. E., \& Kitchen, P. J. (2004). Managing the changes in corporate branding and communication: closing and re-opening the corporate umbrella. Corporate Reputation Review, 6(4), 347-366. 
https://doi.org/10.1057/palgrave.crr.1540004

Scott, D. M. (2015). The new rules of marketing and PR: How to use social media, online video, mobile applications, blogs, news releases, and viral marketing to reach buyers directly. John Wiley \& Sons.

Siano, A., Fiocca, R., \& Pastore, A. (2015). L'avvento del Content Marketing: dalla pratica alla teoria. Mercati e Competitività, Special Issue, 1, 17-23.

Siano, A., Vollero, A., Confetto, M. G., \& Siglioccolo, M. (2013). Corporate communication management: A framework based on decision making with reference to communication resources. Journal of Marketing Communication, 19(3), 151-167. https://doi.org/10.1080/13527266.2011.581301

Singer, J. B. (2014). User-generated visibility: Secondary gatekeeping in a shared media space. New Media \& Society, 16(1), 55-73. https://doi.org/10.1177/1461444813477833

Smith, T. (2009). The Social Media Revolution. International Journal of Market Research, 51(4), 559-561. https://doi.org/10.2501/s1470785309200773

Taylor G. (2012). Digital Content Marketing. United States of America: CreateSpace Independent Publishing Platform.

Trusov, M., Bukclin, R. E., \& Pauwels, K. (2009). Effects of Word-of-Mouth Versus Traditional Marketing: Findings from an Internet Social Networking Site. Journal of Marketing, 73(5), 90-102. https://doi.org/10.1509/jmkg.73.5.90

Tuten, T. L., \& Solomon M. R. (2015). Social Media Marketing. California: Sage Publications Ltd.

Van Ruler, B., \& Verčič, D. (2005). Reflective Communication Management: Future Ways for Public Relations Research. In P. J. Kalbfleisch (Ed.), Communication yearbook (Vol. 29 No. 1, pp. 239-274). Mahwah, NJ Erlbaum. https://doi.org/10.1080/23808985.2005.11679049

Vollero, A., \& Palazzo, M. (2015). Conceptualizing Content Marketing: A Delphi approach. Mercati e Competitività, 1, 25-44. https://doi.org/10.3280/mc2015-001003

Welch, M., \& Jackson, P. R. (2007). Rethinking internal communication: A stakeholder approach. Corporate Communications: An International Journal, 12(2), 177-198. https://doi.org/10.1108/13563280710744847

Winer, R. S. (2009). New Communications Approaches in Marketing: Issues and Research Directions. Journal of Interactive Marketing, 23(2), 108-117. https://doi.org/10.1016/j.intmar.2009.02.004

\section{Copyrights}

Copyright for this article is retained by the author(s), with first publication rights granted to the journal.

This is an open-access article distributed under the terms and conditions of the Creative Commons Attribution license (http://creativecommons.org/licenses/by/4.0/). 